\title{
Conditioned reinforcement: Neglected or outmoded explanatory construct?
}

\author{
BEN A. WILLIAMS \\ University of California, San Diego, La Jolla, Califormia
}

\begin{abstract}
The construct of conditioned reinforcement has been challenged over the past two decades, both as an adequate explanation of behavior in various situations (e.g., behavioral chains) in which it was previously regarded as crucial and in terms of the validity of the concept of conditioned value on which it is based. Recent research is reviewed that answers these criticisms and vindicates the importance of the construct. Also discussed are unanswered empirical issues regarding the concept and its implications for behavioral phenomena of major importance for general-process learning theory, such as autoshaping and imprinting.
\end{abstract}

In reaching our goal [of understanding human behavior] the principle of secondary reinforcement will be of great analytical assistance.... It gives a powerful and indispensable tool for the solution of many vexing and absorbing problems of human action. (Keller \& Schoenfeld, 1950, p. 260)

Although it is characteristic of human behavior that primary reinforcers may be effective after a long delay, this is presumably only because intervening events become conditioned reinforcers. (Skinner, 1953, p. 76)

There is probably no concept in all of psychology that is in such a state of theoretical disarray as the concept of secondary reinforcement. (Bolles, 1967)

During the period from 1940 to 1960 , when behavior theory was the dominant explanatory framework for psychology, the concept of conditioned (secondary) reinforcement - the idea that stimuli paired with primary reinforcers acquire reinforcement properties in their own right - played a central role in extrapolating to human behavior the concepts of reinforcement developed in the animal laboratory. Human motives and values were regarded as only minimally determined by biological drives and thus were primarily the result of learning. The idea that arbitrary events could acquire value through conditioning was regarded as the key to human socialization, a view that was richly elaborated by the affiliates of the Institute of Human Relations at Yale University under the aegis of Clark Hull. (For a review of this early research, see Miller, 1951.) Throughout this period, such major figures as Neal Miller, O. H. Mowrer, Robert Sears, John

Preparation of this paper, as well as much of the research, was supported by NSF grants to the author, who thanks Seth Roberts, Linda Hayes, and Edmund Fantino for their comments on earlier drafts. Reprint requests should be addressed to B. A. Williams, Department of Psychology, University of California, San Diego, La Jolla, CA 92093-0109 (e-mail: bawilliams@ucsd.edu)
Whiting, John Dollard, and several others applied the notion of conditioned value to such diverse topics as personality theory, psychopathology, and social behavior (e.g., Dollard \& Miller, 1950; Miller \& Dollard, 1941; Mowrer, 1950). As is clear from the first two quotes beginning this paper, Keller and Schoenfeld, as well as Skinner, shared this enthusiasm for the explanatory power of the concept of conditioned reinforcement and regarded it as essential for extending reinforcement theory to the analysis of human behavior in the real world.

To judge by the treatment of conditioned reinforcement in recent textbooks on learning, the perception of its importance has receded substantially. In contrast to the typical chapter-length treatment of the topic in learning texts of a generation ago (e.g., Kimble, 1961; for an entire book devoted to the topic, see Wike, 1966), it now receives cursory treatment, often consisting of no more than a definition and a few examples of its application. For example in possibly the best selling learning text, The Principles of Learning and Behavior (Domjan \& Burkhard, 1986), less than a single page is devoted to the concept. Generally absent from such treatments are considerations of how the concept might be applied to other behavioral phenomena. This reduced emphasis on the concept is evident even in texts whose authors are strongly within the behavior analysis tradition. The recent third edition of Chance's introductory text, Learning \& Behavior (1994), for example, contains a single paragraph devoted to the concept. Paradoxically, this decrease in interest has occurred during a period when the parallel concept of second-order conditioning in the arena of Pavlovian conditioning has been the subject of intensive experimental research and theoretical analysis (see Rescorla, 1980).

What accounts for this decline of interest in the concept? One possibility might be that the issues surrounding it are viewed as resolved, so that exposition is reserved for other topics that are the subject of more 
current vigorous debate. Alternatively, the rise in influence of cognitive interpretations of animal learning has caused all types of reinforcement-based explanations to diminish in appeal, and the texts are simply reflecting this change in their audience. But more likely the crucial reason for the reduced status of the topic is that considerable disagreement now exists even within the community of behavior theorists about the validity of the concept as an explanatory tool.

\section{Examples of Conditioned Reinforcement}

At an empirical level there can be little doubt that experimental operations in which once-neutral stimuli are contingent on operant behavior may substantially affect both the rate and pattern of that behavior. Among the most influential of such demonstrations is a series of experiments by J. Zimmerman and his collaborators that were conducted between 1959 and 1967; one of them (Zimmerman, Hanford, \& Brown, 1967) will be described here. In this experiment, food was presented to pigeons on a background schedule of freely presented reinforcement with an average time between free reinforcers of $3 \mathrm{~min}$ [known technically as a variable-time (VT) $3 \mathrm{~min}$ ], with the additional contingency that any scheduled food presentation was delayed until $6 \mathrm{sec}$ had elapsed without a response. This contingency was included to ensure that pecking behavior was not adventitiously followed by food. Conditioned reinforcers consisted of brief presentations $(0.5 \mathrm{sec})$ of the stimulus complex that ordinarily accompanied food presentation - namely, the darkening of the response key, extinction of the houselight, and the sound of the operation of the food tray. Different frequencies of conditioned reinforcement were then presented across different experimental conditions. Response rate tracked the frequency of conditioned reinforcement, with a typical rate of 5-7 pecks per min with the highest rate used-a variableinterval (VI) $1 \mathrm{~min}$. Training conditions were continued for 15-20 sessions for each set of schedule values, with no indication that response rate was decreasing with continued training. In earlier experiments, response rate was shown to decrease to near-zero levels when stimuli different from those paired with reinforcer delivery were contingent on pecking. Similarly, response rate also decreased to low levels when the schedule of free food was suspended, which meant that the stimuli serving as conditioned reinforcers were no longer paired with food. These results thus suggest that schedules of conditioned reinforcement can maintain behavior continuously in a manner apparently similar to that which occurs with primary reinforcement.

A second example of the power of conditioned reinforcement to sustain high levels of behavior comes from the use of second-order schedules of brief-stimulus presentation. With such schedules, a long interval between presentations of the primary reinforcer is subdivided into smaller units, after each of which a brief stimulus is presented; this stimulus then also appears at the end of the interval, contiguous with the primary reinforcer. Kelleher (1966), for example, put pigeons on a fixedinterval (FI) 2-min schedule of brief-stimulus presentations, 30 completions of which were required for food delivery, for a total interfood interval of $60 \mathrm{~min}$. In general, behavior was well maintained under the briefstimulus schedules, with response rates of approximately 30 pecks $/ \mathrm{min}$, despite the extremely low food rate. In the absence of the schedule of brief stimuli, the response rate was much lower.

\section{Challenges and Alternative Interpretations}

Given the evident power, seen in the preceding examples, of conditioned-reinforcement contingencies to control behavior, why has the validity of the concept of conditioned reinforcement been a subject of dispute? The controversy has not been whether contingent stimuli may affect behavior, because clearly they do; at issue, rather, has been whether such effects depend upon the stimuli having acquired conditioned value as a result of their pairing with the primary reinforcer. In a textbook treatment of the topic, Rachlin (1976) argues that the effectiveness of putative conditioned reinforcers is due to the operation of two separate mechanisms by the stimulus, neither of which depends upon it having acquired conditioned value in its own right. One of these mechanisms is simply to highlight that a response has registered, in much the same sense as response feedback is commonly used (e.g., a brief flash of the keylight whenever the microswitch has closed). The other is that it signals that a reinforcer is about to occur, thus serving to bridge the gap between the response and the subsequent reinforcer. While both of these effects may be facilitated somewhat by the stimulus being paired with the primary reinforcer (perhaps by the salience of the stimulus being enhanced), neither depends on the stimulus having acquired conditioned value.

To demonstrate the implausibility of the concept of conditioned value, Rachlin (1976) offers an analogy of choosing between two hotels. At one, a dinner bell (the putative conditioned reinforcer) is sounded prior to mealtimes. The other hotel is identical, except that the same dinner bell is sounded not only prior to mealtimes, but at other times as well. Rachlin argues that if the bell has acquired conditioned value, one's preference should be to stay in the hotel with the additional bell presentations, whereas intuition suggests that exactly the opposite would occur-namely, that one's preference would be for the hotel with fewer bell presentations.

Support for Rachlin's (1976) intuition argument comes from the results of Schuster (1969), who used a concurrent-chains procedure with pigeons. This procedure, which is outlined in Table 1, involves a choice between chain schedules. The subject initially works on two concurrently available alternatives, each associated with its own reinforcement schedule (typically, VIs of equal value). Whenever either of these initial-link schedules is completed, a new stimulus appears, along with 
Table 1

Outline of the Concurrent-Chains Procedure Used by Schuster (1969)

\begin{tabular}{|c|c|c|}
\hline & Left & Right \\
\hline $\begin{array}{l}\text { Initial Link } \\
\text { (Choice Phase) }\end{array}$ & $\mathrm{VI} 1 \mathrm{~min}$ & VI $1 \mathrm{~min}$ \\
\hline $\begin{array}{l}\text { Terminal Link } \\
\text { (Single Stimulus) }\end{array}$ & $\begin{array}{l}\text { VI } 30 \mathrm{sec} \text { (food) and FR } 11 \\
\text { for briefly presented stimulus }\end{array}$ & VI $30 \sec ($ food $)$ \\
\hline
\end{tabular}

Note-The consequence of choice in the initial link was access to one or the other terminal-link stimulus. Consequences of responding in the terminal links were food and, for one terminal link only, presentation of the brief stimuli associated with food delivery.

the terminal link of the chain appropriate to the selected initial-link response. During either terminal link, the other key becomes dark and inoperative, which means that choice is only possible during the initial link of the chains, not during the terminal links. Responses in the presence of the terminal-link stimuli earn primary reinforcement on some schedule. In most experiments, a single primary reinforcement reinstates the initial link, and the entire procedure recycles. In Schuster's particular variation of the procedure, the different choice alternatives (the initial links of the schedules) led equally often to different stimuli (the terminal links of the different chain schedules), that were themselves equally correlated with food. In addition, during one of the terminal links, a conditioned reinforcer (the brief stimulus correlated with food presentation) was presented on a fixedratio (FR) 11 schedule. The response rate during that terminal link was higher than that in the alternative terminal link that lacked the brief-stimulus presentations, indicating that the contingency had been effective. However, preference for that terminal link, as measured by the choice proportion during the initial link of the schedule, was substantially reduced below that for the alternative terminal link that lacked the brief stimuli. Thus, instead of enhancing the value of the terminal link in which they occurred, the additional presentations of the food-paired cues actually seemed to lessen it.

This finding - that while the response rate increased during the terminal link in which the additional stimulus presentations occurred, preference for that terminal link was decreased-suggests that increases in response rate may not be taken as valid evidence for the occurrence of conditioned value (see Pearce \& Collins, 1987; Williams, 1991a, for similar dissociations). A possible reason for this dissociation is that the operations used to assess conditioned reinforcement--additional nonreinforced presentations of a stimulus otherwise paired with food-are identical to those used to produce "frustration," which is assumed to be an aversive drive state (for a review, see Mackintosh, 1974, pp. 261-268). For example, rats will jump from a goal compartment to escape a stimulus associated with nonreinforcement after previous exposure to reinforcement in the same situation (Daly, 1969). The possible implication is that increases in response rate that are supposedly due to conditioned reinforcement may in fact be reflecting not the operation of conditioned value, but rather, only the arousal properties of conditioned frustration.

Support for Rachlin's (1976) analysis of the alternative ways in which conditioned reinforcers may facilitate behavior also comes from subsequent research that has provided strong support for the empirical reality of such effects, which are quite independent of any effect of conditioned value. The concept of marking has been developed in a series of studies in which the presentation of brief distinctive stimuli has been contingent on choice responses in a two-choice simultaneous discrimination involving a delay of reinforcement between the choice and the outcome. The critical feature of the marking procedure is that the brief-stimulus presentation occurs regardless of whether the choice was for the $\mathrm{S}+$ or the $\mathrm{S}-$. Thus, any effect of conditioned value should strengthen correct and incorrect choices equally and should not have any differential effect on the rate of acquisition of the discrimination. Nevertheless, marking procedures have been shown to substantially facilitate the rate of learning in comparison with conditions in which no signal is presented during the delay-of-reinforcement interval (Lieberman, Davidson, \& Thomas, 1985; Lieberman, McIntosh, \& Thomas, 1979). The interpretation of this facilitation has been that the brief stimulus perceptually isolates the choice response, making it more salient in memory at the time the response consequence is eventually delivered at the end of the delay interval.

The second mechanism suggested by Rachlin (1976) as an alternative to a conditioned-value interpretation of conditioned reinforcement effects, whereby the stimulus in the delay-of-reinforcement interval serves to bridge the temporal gap between the response and primary reward, has also received empirical support. A method for distinguishing between bridging versus conditionedvalue effects has been developed by Rescorla (1982) in his analysis of the role of second-order conditioning in serial conditioning procedures using an autoshaping preparation. The role of second-order conditioning in Pavlovian conditioning is conceptually the same as the role of conditioned reinforcement in operant conditioning, so that any effect applicable in one domain is likely to occur in the other. The crucial procedure used by Rescorla to separate conditioned value from bridging is depicted in Table 2. Two separate target stimuli, $\mathrm{A}$ and $\mathrm{B}$, were randomly presented on different trials, on $50 \%$ of which food occurred after a delay interval. Also on $50 \%$ of the presentations of $\mathrm{A}$ and $\mathrm{B}$, a third stimulus, $\mathrm{X}$, was presented immediately after each stimulus. Presumably these pairings also served to increase the level of conditioning to $\mathrm{A}$ and $\mathrm{B}$, due to second-order conditioning, because X itself terminated in food on $50 \%$ of the trials. Note that these two separate sources of conditioning-delayed primary reinforcement and immediate conditioned reinforcement - were equated for the two target stimuli, so that there should have been no difference in the level of behavior they elicited. However, condi- 
Table 2

Outline of the Events on Individual Trials of the Bridging Procedure of Rescorla (1982)

\begin{tabular}{ccl}
\hline CS & Delay Interval & Outcome \\
\hline A & X & Food \\
A & Blank & No Food \\
B & Blank & Food \\
B & $X$ & No Food
\end{tabular}

Note-Each of two stimuli appeared on half of the trials, with food after a 5 -sec delay on $50 \%$ of the stimulus presentations. The stimuli differed with respect to whether the intervening stimulus, $X$, occurred on food or on no-food trials.

tioning occurred more rapidly to Stimulus A. The critical difference between the two target stimuli was whether Stimulus $X$ bridged their respective delays to food. Despite $X$ being paired with the two target stimuli with equal frequency, the gap between Stimulus $\mathrm{A}$ and food was bridged by $\mathrm{X}$, whereas no such bridging function occurred for Stimulus B. The implication is that many effects of conditioned-reinforcement contingencies might similarly be due to such a bridging function.

The challenges to conditioned value posed by Rachlin (1976), and the apparent empirical reality of marking and bridging as processes separate from those of conditioned value, combine to question whether the concept of conditioned value is in fact necessary. It thus becomes worthwhile to consider whether classic demonstrations of conditioned-reinforcement effects, such as the two examples considered earlier (Zimmerman et al., 1967; Kelleher, 1966) really do require invoking some role for the concept of conditioned value.

The results of Zimmerman et al. (1967) cannot be explained in terms of either marking or bridging, since both depend on the contingent stimulus facilitating the associative connection between the response and the delayed primary reward, whereas the actual food contingency employed by Zimmerman et al. was between not responding and food delivery. However, features of their study do allow an alternative interpretive possibilitythat responding was maintained by the reinforcing effects of the brief-stimulus presentations quite apart from their having been paired with food themselves, perhaps because of the inherent sensory reinforcement properties of such stimuli (see Kish, 1966, for a discussion of sensory reinforcement). The control conditions used by Zimmerman et al. were interpreted to show that the observed conditioned-reinforcement effects did depend upon the pairing with food, in that peck rate declined to a near-zero level when stimuli not paired with food were made contingent on responding, as well as when food deliveries were discontinued. However, the first of these findings was confounded because the unpaired stimuli (keylight changes) were very different from the paired stimuli (food-magazine cues), so it is possible that pairing, per se, was not the critical variable. The interpretative value of the second finding can also be questioned, since it is possible that the sensory-reinforcement prop- erties of contingent stimuli may depend upon the incentive motivational effects of food in the environment - an idea empirically supported by Herrnstein and Loveland (1972; see also Herrnstein, 1977). The result is that the often-cited results of Zimmerman et al. cannot be unambiguously interpreted in terms of conditioned value after all.

The explanation in terms of conditioned value of the effects of second-order schedules, such as that of Kelleher (1966), has also been challenged. Fantino (1977) argued that the underlying process was better described as "conditioned confusion," and Staddon (1983) has provided a similar explanation. This interpretation is based on the assumption that the brief-stimulus presentation preceding the last component of the overall food schedule is sufficiently close to the food contingency that it serves as an effective cue for the imminent availability of food. In Kelleher's experiment, for example, the penultimate presentation of the brief stimulus occurred 2 min before food was earned, and thus could have served as a potent cue for responding because this $2-\mathrm{min}$ interval was much shorter than the total interfood interval of $1 \mathrm{~h}$. The acquisition by the brief stimulus of the ability to signal food availability then carried over to the occasions when the stimulus was presented earlier in the food interval, in effect confusing the subject into responding as if it were nearer to food availability than it actually was. Thus, the response rates obtained earlier in the food interval were elevated by the brief-stimulus presentations, but this occurred as a result of their discriminative properties, not because they acquired conditioned value.

In addition to the situations just described, other empirical findings that have traditionally been regarded as evidence for the operation of conditioned reinforcement have also been interpreted as representing something other than the acquisition of conditioned value. Among these are chain schedules of reinforcement, perhaps the most important case because of the use of chaining as a ubiquitous explanatory framework for understanding complex human behavior. Traditional analyses of chainschedule performance (e.g., Keller \& Schoenfeld, 1950) have assumed that the reinforcer maintaining such behavior is not the food at the end of the chain, but rather, access to the stimulus for the next link in the chain. Thus, the stimulus for the terminal link both serves as a discriminative stimulus cuing that responding will earn the primary reward and acquires value in its own right because of its direct association with food. The middlelink stimulus (of a three-link chain) serves as a discriminative stimulus cuing that responding will earn the terminal-link stimulus and also acquires value because of its association with the terminal-link stimulus, via the process of higher-order conditioning. Responding during the initial-link stimulus then occurs because of the contingency between responding and the onset of the middle-link stimulus. The graded response rates across the different links of the chain are explained by each ad- 
ditional link having increasingly less value because each additional step of higher-order conditioning attenuates the level of value transmission.

In contrast to this traditional interpretation, Staddon (1983) has explicitly negated the importance of the concept of conditioned reinforcement for chain schedules, as illustrated by the following quote from his important book:

The concept of conditioned reinforcement (that is, the response contingency between pecking and stimulus change) adds nothing to our understanding of chain schedules.... Provided the response contingency for food in the terminal links is maintained, it [the response contingency for stimulus change] can be omitted in earlier links with little effect on key pecking, as long as stimulus changes continue to take place as before.... Behavior on chain schedules is determined by temporal proximity to food. (p. 466)

To paraphrase Staddon's (1983) argument, the concept of conditioned reinforcement can be dispensed with because the controlling variable for behavior in each link of the chain is the temporal distance to the end of the chain signaled by the individual stimuli composing the chain sequence. This implies that the initial-link stimuli are associated with the primary reinforcer at the end of the chain in the same qualitative manner as the terminal-link stimuli, although with a weaker ability to evoke responding because they cue a greater temporal distance to reinforcement.

The common theme to all of the challenges to conditioned reinforcement that have been considered is that it is their discriminative properties, not their conditioned value, that determine the ability of stimuli to control behavior. In other words, each individual stimulus provides information about the occurrence of the primary reward, and this information value is sufficient to understand how behavior is maintained, without need for recourse to the invention of stimulus "sub-goals" to provide more immediate reinforcement. Thus, the challenge to conditioned reinforcement is sponsored, at least in part, by a rejection of the view that reinforcement contingencies require immediate response feedback for behavior to be maintained. The controlling variable is instead assumed to consist of the molar relationships between responding and reward, even when those relationships extend over substantial temporal intervals. (For an explicit theoretical statement of such a molar theory of reinforcement, see Baum, 1973.)

The aforementioned challenges to the traditional concept of conditioned reinforcement by several of the most prominent and influential of the current generation of behavior theorists provide a significant reason for scrutinizing the empirical support for the concept, as well as for attempting to increase the power of the evidence to provide a clear resolution. In order to test the validity of these challenges, research in our laboratory over the past several years has addressed the role of conditioned reinforcement in several different situations.

\section{Determinants of Behavior Under Chain Schedules}

To assess Staddon's (1983) explicit claim that the conditioned-reinforcement contingency is irrelevant in maintaining chain-schedule behavior, Royalty, Williams, and Fantino (1987) added a brief unsignaled delay of reinforcement to the contingency between the response in one link of the chain and the onset of the succeeding link. The rationale was based on the finding that similar delay-of-reinforcement contingencies have been shown to produce large decrements in behavior (on the order of $70 \%-90 \%$ ) when imposed on primary reinforcement contingencies (Catania \& Keller, 1981; Sizemore \& Lattal, 1978; Williams, 1976a). Thus, if behavior during the early links of the chain is maintained by the conditionedreinforcement properties of the stimulus paired with the transition to the next link of the chain, inserting a delay between responding and stimulus onset should produce a decrement in performance similar to that obtained with delayed primary reinforcement. The baseline schedule was a three-link chain in which each of the three successive stimuli were correlated with a VI-33-sec schedule for advancing to the next link of the chain (or to food, for responding in the terminal link of the chain). The contingency between responding in the initial and middle links of the chain and food at the end of the chain was held constant throughout the experiment by shortening the VI schedule by $3 \mathrm{sec}$ whenever a 3-sec delayof-reinforcement contingency was in effect (becoming a VI-30-sec schedule with a 3-sec delay). In other words, the delay contingency postponed the presentation of the stimulus correlated with the next link of the chain by $3 \mathrm{sec}$ or less, but did not alter the relation between responding in the earlier links of the chain and food delivery. The results were that the delay contingency with respect to stimulus change produced effects on responding essentially like those previously described for food contingencies. When the delay contingency was in effect for the advancement from the initial to the middle link of the schedule, response rate in the initial link was decreased by $75 \%-80 \%$, with no effect on responding in the middle and terminal links of the chain. Similarly, when the delay occurred with respect to the advancement from the middle to the terminal link of the chain, responding in the middle link was reduced by $60 \%-70 \%$, again, with no effects on responding in either of the other links of the chain. The specificity of the delay variable leaves little doubt that the contingency between responding and the onset of the stimulus of the succeeding link of the chain was crucial for maintaining the behavior, directly contradicting the claim of Staddon cited above.

Although the results of Royalty et al. (1987) show clearly that the contingency between responding in the early links of the chain and stimulus onset of the succeeding link is essential to chain-schedule performance, they tell us nothing unequivocally about whether the effect of the stimulus onsets was due to their having acquired conditioned value. Perhaps, for example, the contingent stimulus presentations produced a marking 
effect, causing the animal to learn more easily that responding in the early links of the chain was necessary for reaching the end of the chain. When stimulus onset was then delayed, the behavior that was marked was no longer restricted to pecking the response key, but could include behaviors that would compete with keypecking. In order to prove the role of conditioned value in maintaining chain-schedule behavior, it is necessary to demonstrate the acquisition of conditioned value with some measure other than the enhancement of response rate.

The most common method for assessing the value of some reinforcement contingency is to measure its relative preference in a choice procedure. The experiment of Schuster (1969) described above was predicated on this premise, and its negative results suggest that the rateenhancement effects of conditioned-reinforcement contingencies may in fact not be accompanied by increases in conditioned value. Indeed, his results suggest the opposite effect, as if the additional presentations of the brief stimuli were serving some type of "frustration" effect.

For several technical reasons (see Gollub, 1970, and the introduction of Williams \& Dunn, 1991a), Schuster's results cannot be considered to constitute the definitive test of the relation between preference and conditioned reinforcement. Consequently, Williams and Dunn (1991a) developed a different and somewhat simpler procedure to determine whether animals prefer to receive additional presentations of a stimulus previously paired with food even when those additional presentations occur in the absence of food [i.e., they developed a different test of the validity of Rachlin's (1976) analogy of the two hotels with dinner bells].

As outlined in Table 3, pigeons were presented with a concurrent schedule in which both choice alternatives led to the onset of the same stimulus, which itself was correlated with an FI-20-sec food schedule. During the baseline phase of the experiment, the frequency with

Table 3

Outline of the Concurrent-Chains Procedure Used by Williams and Dunn (1991a)

Reinforcement Schedule

\begin{tabular}{lll}
\multicolumn{3}{c}{ Reinforcement Schedule } \\
\hline \multicolumn{3}{c}{ Center-Key Responding Produced Food } \\
$\begin{array}{l}\text { Initial Link } \\
\text { (Choice) }\end{array}$ & Left (VI 2 min) & Right (VI 2 min) \\
$\begin{array}{lll}\text { Terminal Link } \\
\text { (Single Stimulus) }\end{array}$ & Center Key & Center Key \\
\multicolumn{1}{c}{ Center-Key } & Responding Produced & No Food \\
Initial Link & Left & Right \\
(Choice) & (VI 30 sec) & (VI 30 sec) \\
& $(p=.8)$ & $(p=.2)$ \\
Terminal Link & Center Key & Center Key \\
(Single Stimulus) & (20 sec of EXT) & (20 sec of EXT) \\
\hline
\end{tabular}

Note-Separate reinforcement schedules, operating simultaneously, determined access to the terminal-link center key when center-key presentations were correlated with food or with extinction. The stimulus on the center key was the same, regardless of the schedule. Center-key presentations ending in food were equal for the two choice alternatives, while extinction presentations occurred on a $4: 1$ ratio, as governed by a probability schedule. which pecking produced this stimulus and the frequency of food at the end of the 20 -sec interval were equal, as determined by independent VI-2-min schedules operative for each choice alternative. The critical manipulation was the superimposition on these equal food schedules of an independent VI-30-sec schedule of presentations of the stimulus correlated with the FI-20-sec food schedule, but now without food at the end of the $20-\mathrm{sec}$ stimulus period (i.e., additional extinction presentations). These additional extinction periods were assigned differentially to the two choice alternatives, $80 \%$ to one alternative and $20 \%$ to the other. Because the two choice alternatives were treated identically except for the frequency of these additional extinction presentations, whether the animals responded more to the alternative associated with the more frequent presentations provided a test of how preference is determined by the frequency of conditioned reinforcement, and thus of whether the stimulus had acquired conditioned value. The results were unequivocal: all subjects strongly preferred the choice alternative associated with more frequent stimulus presentations correlated with extinction. Thus, unlike the results of Schuster (1969), these results show that stimuli paired with food are valued by the subject even on those occasions when they occur without terminating in food presentation. The results of Williams and Dunn (1991a) thus make a strong case for the importance of the role played by conditioned reinforcement in chain schedules, and, more generally, for the conditioned-value interpretation of conditioned reinforcement.

\section{Substitutability of Conditioned and Primary Reinforcement}

Further evidence for the generality of the concept of conditioned value has been provided with a very different procedure by Williams and Dunn (1991b). In this case, instead of response rate or preference being the measure of conditioned-reinforcer efficacy, the rate of learning in the repeated acquisition of a simultaneous discrimination was examined. After learning a given problem to a criterion of 10 consecutive correct choices, the reward values of the different stimulus-response combinations were reversed, and during the next session, the reversal was learned to the same criterion. For example, on Reversal N, a white noise signaled that the left response lever was correct, while a panel light signaled that the right response lever was correct; on Reversal $\mathrm{N}+1$, the noise signaled that the right lever was correct and the light signaled that the left lever was correct. The stimulus events during a delay-of-reinforcement interval were then varied across blocks of reversals. Previous research with this procedure (e.g., Williams, 1971, 1976b, 1981) had shown it to be a useful method for studying the within-subject effects of various parameters of reinforcement.

On a specified percentage of trials, correct choices were reinforced by food, which was delivered 5 sec after the choice response, with a tone being presented during 
the 5-sec delay interval. Incorrect choices produced only the onset of the intertrial interval (ITI). The critical variable concerned what happened on trials in which correct choices were not followed by food. When nonreinforced correct choices produced the same feedback as incorrect trials (i.e., the onset of the ITI), the number of trials to reach the acquisition criterion was, not surprisingly, substantially increased by smaller percentages of reinforcement. When the tone signal was added on nonreinforced correct trials, the number of trials required to reach the learning criterion was greatly reduced, and often was similar to that required when correct choices were followed by tone + food on $100 \%$ of the trials. In other words, the occurrence of the tone without food was almost as effective in strengthening the correct choice as the occurrence of the tone + food. This effect depended critically on the tone itself being paired with food, because when it was presented on nonreinforced correct trials but not on food trials, it did not improve the rate of learning over that which occurred when no stimulus occurred on nonreinforced correct trials.

The degree to which the tone-alone presentations could substitute for the tone + food presentations could be described quantitatively, and was found to depend on the frequency of the trials on which food was presented. When $50 \%$ of the correct choices were followed by food, the tone without food was, on average, worth .7 of a tone + food presentation, but when $30 \%$ of the correct trials were followed by food, the tone alone was worth only .4 of a tone + food presentation. This decrease in the effectiveness of the tone as a conditioned reinforcer presumably occurred because the different percentages of food after correct trials corresponded directly to the percentage of trials on which the tone was itself paired with food. Thus, the smaller the percentage of trials on which the tone was paired with food, the smaller the degree of its conditioned value should be. The important feature of the findings of Williams and Dunn (1991b) is not in depicting the precise nature of how conditioned value varies with the parameters of reinforcement, but in demonstrating that a stimulus paired with reinforcement can substitute, at least partially, for a primary reinforcer in facilitating the learning of a discrimination.

A final example of the validity of the conditionedvalue interpretation of conditioned reinforcement effects comes from a provocative study by Cronin (1980), which pitted contingencies of immediate conditioned reinforcement against contingencies of delayed primary reinforcement. Pigeons were presented with a simultaneous discrimination with a 60 -sec delay of reinforcement; correct choices were followed at the end of the delay by food, while incorrect choices were followed at the end of the same interval by no food. When the same stimulus conditions were present throughout the delay after both correct and incorrect choices, acquisition of the discrimination failed to occur even after 30 sessions of training. When choice of the $S+$ versus the $S-$ was followed by different stimuli extending throughout the delay interval, rapid acquisition occurred. Thus, differential stimuli during the delay interval strongly facilitated learning under conditions of delayed reinforcement. The issue becomes how to characterize the nature of those stimulus effects. The critical condition was that of a "reversed-cue" group, which received one color of houselight (e.g., yellow) for the first $10 \mathrm{sec}$ after an S+ choice, and then a different houselight color (e.g., blue) during the last $10 \mathrm{sec}$ of the delay prior to food. After an $S-$ choice, the houselight presentations were reversed, the blue houselight occurring immediately after an Schoice, and the yellow houselight occurring during the last $10 \mathrm{sec}$ of the $60-\mathrm{sec}$ delay before the onset of the next ITI. This reversed-cue condition not only failed to produce discrimination acquisition, it produced a consistent choice (approximately $90 \%$ ) of the $\mathrm{S}-$ stimulus. Thus, preference for the conditioned reinforcer was sufficiently strong that it controlled behavior at the expense of primary reinforcement, a result that can only be interpreted as showing that the immediate conditioned reinforcer possessed considerable value in its own right.

\section{Dissociating Different Types of Stimulus Effects: Conditioned Value versus Bridging and Marking}

The preceding examples make a strong case that the traditional concept of conditioned reinforcement, which relies on a previously neutral stimulus acquiring conditioned value because of its own pairing with a primary reinforcer, is fundamentally valid, and cannot be displaced by alternative conceptions that have been proposed for how such stimuli affect behavior. Moreover, it is clear that the concept of conditioned value is essential for understanding how behavior is maintained even when temporally distant from the primary reinforcer, as in chain-schedule performance, and that it is critical in understanding how conditioned reinforcers may facilitate the acquisition of learning. These demonstrations do not mean, however, that conditioned value is the only means by which contingent stimuli affect behavior, since, as noted above, other types of stimulus effectsnamely, marking and bridging-do appear to operate in at least some situations. At issue, therefore, is the relative contribution of these different types of stimulus effects. While any particular set of reinforcement contingencies will require its own specific functional analysis to assess the relative contributions of these different processes, a general sense of their effects can be gained by examining several situations in which the effects have been directly compared.

An attempt was made by Williams (1991b) to directly compare the explanatory power of the traditional concept of conditioned reinforcement with that of marking and bridging. The repeated-acquisition procedure using blocks of reversals of the reward contingencies with respect to the two discriminative stimuli, which was described above for Williams and Dunn (1991b), was used here as well, with the critical variable being the events occurring during the delay-of-reinforcement interval. 
Table 4

Stimuli Appearing in the Delay Interval Between Choice and Outcome for the Different Experimental Conditions of Williams (1991 b)

\begin{tabular}{lll}
\hline \multicolumn{1}{c}{ Condition } & After S+ Choice & After S- Choice \\
\hline No Signal & & \\
Conditioned Reinforcement & Continuous tone & \\
Brief Conditioned Reinforcement & $1-\sec$ tone & \\
Marking & $1-\sec$ tone & $1-\sec$ tone \\
Bridging & Continuous tone & Continuous tone \\
\hline
\end{tabular}

The different stimulus conditions are outlined in Table 4. For the no-signal condition, no differential stimuli followed choice of the S+ over the S- (more precisely, the conditions present during the ITI also occurred during the delay interval). Not surprisingly, the speed of acquisition was generally slow. The traditional conditionedreinforcement condition differed from the control condition in that a tone was presented throughout the delay interval following choice of the $\mathrm{S}+$, but no stimulus was presented following $\mathrm{S}-$ choices. A second, brief conditioned-reinforcement condition was also studied, in which the tone after choice of the S+ only occurred during the first $1 \mathrm{sec}$ of the delay interval. For the marking condition, the $1-\mathrm{sec}$ tone occurred after choice of both the $\mathrm{S}+$ and the $\mathrm{S}-$, while for the bridging condition, the tone continued throughout the delay interval after choice of both the $\mathrm{S}+$ and the $\mathrm{S}-$. The rationale for the latter two conditions was that marking and bridging both imply that the stimulus function during the delay interval should be one of enhancing the associative linkage between the choice and the outcome, so that the occurrence of the stimulus after an S- choice should increase its association with the absence of reinforcement, and thus enhance the rate of learning over that when the stimulus only occurred after the choice of the $\mathrm{S}+$. Thus, faster acquisition of the discrimination should occur under the marking and bridging conditions than under the conditioned-reinforcement conditions in which the stimulus only occurred after an $\mathrm{S}+$ choice. If, on the other hand, conditioned value is critical to the procedure, the occurrence of the signal after choice of the Sshould strengthen that incorrect behavior, with the effect that the resulting response competition with correct responding should retard the rate of acquisition.

The results were that both the traditional conditionedreinforcement procedure and the brief conditionedreinforcement procedure greatly facilitated the rate of learning relative to the no-signal control condition, reducing the number of trials required to reach the learning criterion by approximately $80 \%$. Neither the marking nor the bridging condition had any facilitatory effect, as the number of trials required to reach criterion under those conditions was approximately equal to that under the no-stimulus control condition. Thus, at least with this one learning procedure, the processes of marking and bridging cannot in any way explain the facilitatory effect obtained under conditioned-reinforcement contingencies.
It can, of course, be argued that the repeated-acquisition procedure is not a fair test of the notions of bridging and marking, perhaps because the use of the same stimulus for all of the different conditions might somehow have produced confusion about the role of the stimulus. The finding that no facilitation occurred with either procedure, while robust effects of marking and bridging have been demonstrated in other procedures, gives some credence to this possibility. To further test the relative explanatory power of the different concepts, we employed the traditional between-subject investigation of the rate of acquisition in a simple learning problem. The dependent variable was the number of sessions required for rats to acquire a leverpress under conditions of delayed reinforcement. The procedure was inspired by the results of Lattal and Gleeson (1990), who demonstrated that naive pigeons and rats could acquire such behaviors, without shaping, using delays of reinforcement as long as $30 \mathrm{sec}$.

\section{EXPERIMENT 1}

In our first experiment, we contrasted the concepts of conditioned value and marking. Different groups of experimentally naive rats received a 30 -sec delay-ofreinforcement contingency. The critical comparison was between the marking condition, in which a signal (an overhead houselight) occurred only during the first $5 \mathrm{sec}$ of the delay, and the conditioned-reinforcement condition, in which the houselight occurred during both the first $5 \mathrm{sec}$ and the last $5 \mathrm{sec}$ of the delay. The critical issue was whether the stimulus itself had to be paired with food in order to facilitate the acquisition of the response.

\footnotetext{
Method

Twenty-three experimentally naive albino male rats (SpragueDawley), ranging in age from 2-4 months, were housed in individual cages and maintained on an 18:6-h light:dark cycle. Each rat was fed daily in its home cage with free access to Purina Rat Chow for $90 \mathrm{~min}$ after the completion of an experimental session. Water was available in the home cage at all times.

Two identical experimental chambers were constructed from Coulbourn modular shells, and included a grid floor, two side walls of clear glass, and ceiling and front and rear walls of aluminum. The height of the interior chamber was $29 \mathrm{~cm}$, its width was $24 \mathrm{~cm}$, and its depth was $31 \mathrm{~cm}$. The interior chamber was enclosed within a larger enclosure for sound insulation and also to provide a masking noise from a ventilating fan. Located in the center of the front panel, $3 \mathrm{~cm}$ above the floor, was the recessed food well, into which 45-mg Noyes pellets (improved
} 
Formula A) were presented from a Gerbrands pellet dispenser. On either side of the food well, $15 \mathrm{~cm}$ above the floor, were stainless-steel retractable levers (Coulbourn model E21-03), $3.7 \mathrm{~cm}$ wide, $0.3 \mathrm{~cm}$ thick, and extending $3 \mathrm{~cm}$ into the chamber when not in the retracted position. A minimum force of $0.25 \mathrm{~N}$ was required for operation. Only the left response lever was used. Mounted near the ceiling in the middle of the front panel was a 28 -V houselight, which projected diffuse light throughout the chamber when illuminated.

During the first two sessions of training, each subject was placed in the experimental chamber for $30 \mathrm{~min}$, with the lever withdrawn, and free food pellets were presented on a VT-60-sec schedule for the purposes of magazine training. On the next session, the lever was inserted throughout and each leverpress was followed $30 \mathrm{sec}$ later by a food pellet. Responses occurring within an already operating delay interval had no further effect. Subjects were divided into three groups, which differed in terms of the stimulus conditions occurring during the 30 -sec delay interval. For the marking condition (B-only condition), the houselight occurred only during the first $5 \mathrm{sec}$ of the 30 -sec delay and was then extinguished for the remainder of the delay. For the conditioned-reinforcement condition (B\&E condition), the houselight was presented during both the first $5 \mathrm{sec}$ of the 30 -sec delay and the last $5 \mathrm{sec}$, just prior to food presentation. For the control subjects (nosignal condition), the houselight was never illuminated, as no differential stimulus change occurred during the delay interval, except for whatever cues were provided by the leverpress itself. Eight subjects were assigned to both the B-only and the B\&E conditions; seven subjects were assigned to the no-signal condition. Ten 30 -min sessions of training occurred for all three conditions.

\section{Results}

As shown in Figure 1, both stimulus conditions facilitated acquisition relative to the no-signal control condition, but the rate of acquisition was substantially faster with the conditioned-reinforcement condition during the first six sessions, although this difference decreased with continued training. The results were assessed with a mixed analysis of variance (ANOVA), with stimulus condition and experimental chamber as between-subject variables, blocks of training a within-subject variable, and a .05 significance level. The effect of experimental chamber was significant $[F(1,17)=5.09]$, but did not interact significantly with either the stimulus condition or the session of training. The effect of stimulus condition was significant $[F(2,17)=6.23]$, and NewmanKeuls paired comparison tests revealed that the B\&E condition was significantly different from both the B-only and the no-signal conditions, but that the latter two conditions were not significantly different from each other. The main effect of blocks of training was also significant $[F(4,68)=20.8]$, as was the interaction between the stimulus condition and blocks of training $[F(8,68)=2.49]$. Analysis of simple effects revealed that the effect of training sessions was significant for the $\mathrm{B} \& \mathrm{E}$ and $\mathrm{B}$-only conditions $[F(4,68)=10.08$ and 14.89 , respectively], but that it was not significant for the no-signal condition. Thus, both conditions with the signal at the onset of the delay of reinforcement produced a significant increase in responding over sessions, while the no-signal condition did not.

\section{Discussion}

The results demonstrate that the facilitation of learning produced by a signal immediately contingent on an

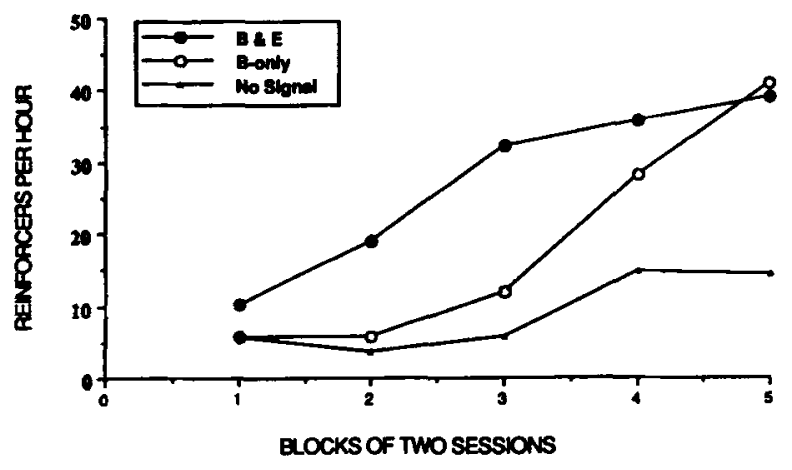

Figure 1. Mean rate of earned reinforcers for subjects trained with a 30-sec delay of reinforcement contingency. Different conditions varied with respect to the stimulus conditions during the delay interval.

operant response was enhanced by having that signal also paired with the food at the end of the delay-ofreinforcement interval. Thus, the highlighting of the response by marking it with a salient signal is not sufficient to explain the facilitatory effects of signals in delayof-reinforcement intervals; a major additional role is played by the value of the signal, which is provided by the signal itself being paired with food at the end of the delay.

Nevertheless, the effect of the signal only at the onset of the delay was quite strong. As shown in Figure 1, the difference between the B-only and B\&E conditions had completely dissipated by the end of the ten sessions of training. Subsequent investigation using much longer periods of training has confirmed the generality of this finding, as the effect of having the stimulus contiguous with food at the end of the delay interval is not reliable once stable levels of behavior are achieved. This is perhaps not surprising, given that other studies (Schaal \& Branch, 1988, 1990) have shown that brief signals occurring only at the onset of a delay interval will sustain high levels of behavior comparable to that achieved when the signal is continuously present during the delay and hence temporally contiguous with the primary reinforcer. It remains uncertain how to interpret those effects, since it is possible that the signal only at the beginning of a delay may be directly associated with the primary reinforcer, despite the long gap between its occurrence and food delivery. Whatever the cause of the unpaired signal effects with steady-state behavior may be, the present data show unequivocally that direct pairing of the signal with the primary reward facilitates acquisition under delayedreinforcement contingencies.

\section{EXPERIMENT 2}

The second experiment was intended to contrast the concepts of bridging and conditioned reinforcement. The test was based on an analogy with real-world bridges, which are functionally useful only if they are continuously present between the two sides they are in- 
tended to connect. Thus, in the bridging condition, a signal (a houselight) was presented throughout the entire 60 -sec delay interval. In the conditioned-reinforcement condition, this stimulus occurred only during the first few seconds and the last few seconds of the delay inter$\mathrm{val}$, the assumption being that, in this case, the stimulus effects, if any, cannot be ascribed to bridging, because bridges with a missing middle should provide a weaker connection between the two sides of the interval. In contrast, however, the critical requirement for the concept of conditioned value is met for both conditions, in that the stimulus immediately contingent on the response is itself paired with the primary reward.

\section{Method}

Sixty experimentally naive subjects, similar in all respects to those described for Experiment 1, served as subjects. The same two conditioning chambers described for Experiment 1 were also used.

On the first two sessions of training, the lever was retracted and food was presented on a VT-90-sec schedule for the purposes of mag azine training. On the next session, the lever was inserted throughout and each leverpress was followed $60 \mathrm{sec}$ later by a food pellet. Responses occurring within an already operating delay interval had no effect. Three experimental conditions were defined by the stimulus conditions occurring during the delay-of-reinforcement interval. For the continuous-signal condition, the houselight was illuminated immediately after a response and remained on for the entire 60 -sec interval, terminating with the food delivery. For the $\mathrm{B} \& \mathrm{E}$ condition, the houselight came on both at the beginning and at the end of the interval, but was extinguished during the middle of the delay interval. The periods of illumination time differed across subsets of subjects within the $B \& E$ condition; for one set, the houselight was on for the first 2 and the last $2 \mathrm{sec}$ of the delay; for a second set, the houselight was on for the first 5 and the last $5 \mathrm{sec}$; and for a third set, the houselight was on for the first 10 and the last $10 \mathrm{sec}$. However, no reliable differences occurred as a function of the stimulus duration, so that data for the $B \& E$ condition were collapsed across the different stimulus durations for all subsequent discussion and analysis. For the no-signal condition, the houselight was not illuminated at any time. Combined over two separate replications, 20 subjects were assigned to the continuous-signal condition, 24 to the $\mathrm{B} \& \mathrm{E}$ condition, and 16 to the no-signal condition. One subject in the $B \& E$ condition was discarded because it never emitted a leverpress at any time during training and hence did not come into contact with the experimental contingencies. Training continued for six 1-h sessions.

\section{Results}

The results for three separate experimental groups are shown in Figure 2. The control condition involved no differential signals during the delay, and no increase in the amount of leverpressing occurred across the entire period of training, indicating that a $60-\mathrm{sec}$ delay of reinforcement was too long to control behavior. The critical comparison is between the two conditions with signals during the delay interval. Both conditions produced acquisition of the leverpress for all subjects, showing that the stimulus during the delay interval strongly facilitated learning. In addition, the rate of acquisition was greater when the signal occurred only at the beginning and end of the delay than when it was continuously present throughout the delay. The results shown in Figure 2 were assessed with a two-way ANOVA, with stimulus condition and replication (two different replications

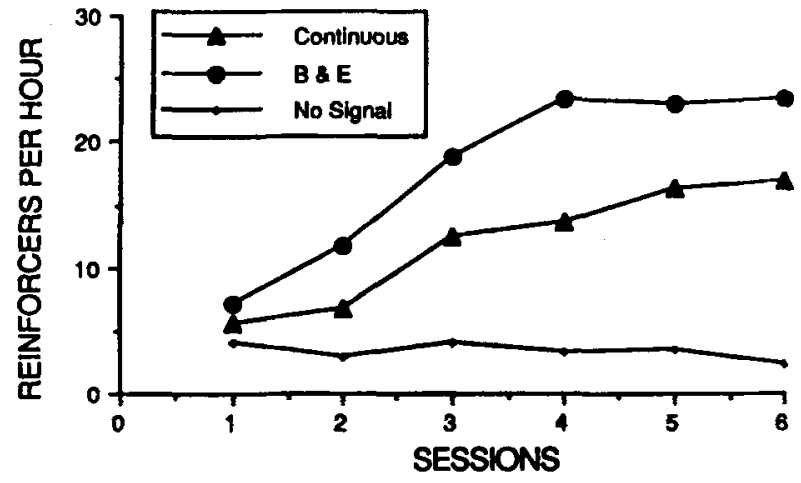

Figure 2. Mean rate of earned reinforcers for subjects trained with a 60-sec delay of reinforcement contingency. Different conditions varied with respect to the stimulus conditions during the delay interval.

were conducted at different times) as between-subject variables, and session of training a within-subject variable. The main effect of stimulus condition was significant $[F(2,53)=17.8]$; in addition, paired comparisons with the Newman-Keuls tests showed that the B\&E condition was significantly different from both the continuous and the no-signal conditions, and that the latter two conditions were also significantly different. The main effect of replication was not significant, nor did it interact with either of the other variables (all $F \mathrm{~s}<1$ ). The main effect of sessions was also significant $[F(5,265)=$ 18.4], as was the interaction between stimulus condition and session $[F(10,265)=6.13]$.

As was the case for the comparison between the B-only and the B\&E conditions of Experiment 1, the difference between the $B \& E$ and the continuous-signal conditions seen in Figure 2 was not sustained when training under the different conditions was continued until behavior reached its asymptotic level. Although not shown in Figure 2, subsequent research using conditions similar to those of Experiment 2 has shown that response rates under the two conditions becomes very similar after 10 or more sessions of training. Thus, differences produced by the different stimulus conditions occur primarily during initial acquisition rather than during the sustained vigor of performance.

\section{Discussion}

The results were exactly the opposite of those predicted by the hypothesis that conditioned-reinforcement effects can be explained by the concept of bridging. Contrary to that notion, the associative connection between two elements is not facilitated by a continuous linkage between the two events. The superiority of the disconnected stimulus presentations is, however, consistent with an account in terms of conditioned value. Accordingly, both the continuous and the B\&E conditions seen in Figure 2 should be expected to facilitate learning because the signal in both cases was contiguous with the food, and thus should have acquired conditioned value. 
In addition, the degree of value acquisition should be a function of the rate of reinforcement per unit of stimulus time. This rate of reinforcement was higher in the $\mathrm{B} \& \mathrm{E}$ condition because the total signal duration was shortened by its deletion during the middle of the interval. Without some appeal to the concept of conditioned value, there seems no way to explain the superior performance in the $\mathrm{B} \& \mathrm{E}$ condition.

The evidence that has been reviewed provides strong support for the conditioned-value interpretation of conditioned-reinforcement effects in several different procedures. It may be that alternative processes, such as marking and bridging, are operating in some of these procedures as well, but whenever these different processes have been directly compared, it is clear that the effects of conditioned value have been dominant. It is now time to consider how conditioned value itself is determined.

\section{GENERAL DISCUSSION}

\section{The Inherent Tradeoff Between Frequency and Value}

As shown by the results of Williams and Dunn (1991b), described earlier, the degree to which a conditioned reinforcer can substitute for a primary reinforcer depends on the percentage of its presentations that are followed by food. This effect is expected from the view that conditioned value results from the Pavlovian association between the stimulus and the reinforcer, because each presentation of the stimulus in the absence of the primary reinforcer serves as an extinction trial. The stimulus should thus lose its conditioned value as a function of the rapidity of the extinction process. The implication is that procedures that hold constant the number of pairings of the conditioned and primary reinforcers while providing additional presentations of the conditioned reinforcer are necessarily intertwining two separate effects that are working in opposite directions. The additional presentations of the stimulus will increase the strength of the behavior, all other things being equal, as shown by Williams and Dunn (1991a). On the other hand, all presentations of the conditioned reinforcer will be of lessened value because each nonreinforced presentation of the stimulus leads to additional extinction. Which effect will be dominant then remains an empirical issue, dependent upon the particular conditioning procedure involved.

Understanding the dynamics of this tradeoff is important in part because it is crucial in understanding the effects of probability of reinforcement, a topic that has led to an important attempt to analyze many of the major phenomena of human decision making from the perspective of behavior theory (Rachlin, Logue, Gibbon, \& Frankel, 1986). The results of Mazur (1991; see also Mazur, 1993) provide an illustration (for related findings, see Branch, 1977). Mazur presented pigeons with a choice between two alternatives, one with $100 \%$ rein- forcement in combination with a titrating delay of reinforcement, and the other with .20 reinforcement probability always with a standard delay interval of $5 \mathrm{sec}$. The value of the titrated delay was then changed from trial to trial until choice between these two probabilities of reinforcement was 50:50. The stable level of the titrated delay thus provided a measure of the value of the partially reinforced alternative: longer delays correspond to lower values for the .20 reinforcement probability. The critical comparisons involved the stimulus conditions on the reinforced and the nonreinforced presentations of the partially reinforced terminal link. When the same stimulus was used for both outcomes, the titrating delay associated with the $100 \%$ alternative averaged $17-18 \mathrm{sec}$, significantly shorter than the $25 \mathrm{sec}$ that would be expected if probability of reinforcement and delay of reinforcement were strictly equivalent. The more important finding for our present purposes is that the titrated delay was substantially shorter-approximately 7-8 secwhen different stimuli were associated with the reinforcer than were associated with the nonreinforced presentations of the partially reinforced terminal link.

To see the relevance of Mazur's (1991) results to the issue of how conditioned reinforcement is determined, consider the dynamics of his two different signaling conditions. When the same stimulus occurred on reinforced and nonreinforced presentations, this meant that $100 \%$ of the choices of that alternative were followed by a stimulus that ended in food on $20 \%$ of its presentations. When different stimuli were associated with nonreinforced than were associated with reinforced presentations, choices of that alternative were followed on $20 \%$ of the trials by a stimulus that always terminated in food, and on $80 \%$ of the trials by a stimulus that never terminated in food. Thus, there was a 5:1 ratio in the frequency of the conditioned reinforcement for the nondifferential versus the differential stimulus conditions, but a 1:5 ratio in the probability of reinforcement correlated with the conditioned reinforcer itself. Mazur's finding that the value of the signaled terminal links was much greater than that of the unsignaled terminal link implies that variation in the probability of reinforcement during the stimulus was much the more potent of the two reinforcement parameters.

\section{Delay Reduction and Stimulus Value}

The preceding discussion should not be taken to imply that the percentage of stimulus presentations paired with the primary reinforcer is the dominant determinant of conditioned-reinforcement value. The most general description of the determinants of conditioned value is that it follows the laws of Pavlovian conditioning. Indeed, one authoritative learning theorist (Mackintosh, 1983) has argued that the efficacy of a Pavlovian conditioned stimulus (CS) as a conditioned reinforcer is often a better indicator of the strength of conditioning to that CS than is the likelihood that the CS will elicit a conditioned response (CR). This con- 
clusion is informative because the main general determinant of Pavlovian conditioning is the degree to which the CS "predicts" the occurrence of the unconditioned stimulus (US), not simply the number or percentage of CS-US pairings. While the question of exactly how the notion of "predictiveness" is to be formulated is still vigorously debated within the Pavlovian theoretical arena (see Durlach, 1989, for a recent review), the fundamental idea is that the value of a stimulus is not determined solely by the absolute temporal relations between the stimulus and the reward, but instead varies with the overall context of reinforcement in which the stimulus occurs. As will be seen, such context effects are fundamental to understanding conditioned reinforcement.

Delay-reduction theory (Fantino, 1977) represents perhaps the most influential attempt to provide an explanatory framework for capturing such context effects. Its basic premise is that the value of a stimulus is determined by how much the onset of the stimulus reduces the expected time to reinforcement, relative to the average time to reinforcement in the situation independent of the stimulus. For example, if the average time between food presentations is $120 \mathrm{sec}$, and the time between the onset of the stimulus and food is $30 \mathrm{sec}$, the stimulus signals a $75 \%$ reduction in the time to presentation of food; but if the average time between presentations of food is $60 \mathrm{sec}$, while the time between the onset of the stimulus and food remains at $30 \mathrm{sec}$, the stimulus would signal only a $50 \%$ reduction in time. It is this degree of improvement signaled by the stimulus, rather than its own absolute temporal relation with respect to food, that determines the value of the stimulus as a conditioned reinforcer.

To see how the quantitative properties of the idea of the delay-reduction principle are implemented, the results of Fantino (1969) will be considered in detail. Fantino presented pigeons with a concurrent-chains procedure in which the initial-link-choice alternatives were always correlated with identical schedules; the different terminal-link stimuli to which they led were also always correlated with the same schedules-namely, VI $30 \mathrm{sec}$ versus VI $90 \mathrm{sec}$. While the ratio of reinforcement rates associated with these two stimuli remained constant at $3: 1$, delay reduction implies that their relative value will vary strongly as a function of the average interreinforcement interval. To manipulate the average interval between food presentations, Fantino used three different initial-link schedules-VI 600, VI 120, and VI $40 \mathrm{sec}$ - which were always equal for the two choice alternatives. The average times to reinforcement produced by these different schedules, summed over both initialand terminal-link times, were $360 \mathrm{sec}, 120 \mathrm{sec}$, and $80 \mathrm{sec}$. The corresponding delay reductions for the VI-30-sec terminal-link schedule were .92, .75, and .63, while those for the VI-90-sec terminal-link schedule were $.75, .25$, and -.11 (negative values referring to the stimulus onset predicting an increase in the time to reinforcement relative to the average). The choice proportions for the shorter terminal-link schedule were then as- sumed to be a function of its proportion of the total of the delay reductions summed over both terminal links [e.g., .92/(.92+.75)], and were $.55, .75$, and 1.0 for the different initial-link schedules. The obtained choice proportions in fact corresponded closely to these predictions. Thus, with long initial-link schedules, preference was near indifference, while with the short initial-link schedule, preference was exclusively in favor of the shorter terminal link, despite the absolute values of the terminal-link schedules remaining unchanged.

A variety of data support the essential idea underlying delay-reduction theory (see especially Preston \& Fantino, 1991). Moreover, its basic assumptions are essentially similar to those of a prominent account of Pavlovian conditioning - the scalar expectancy theory of Gibbon and Balsam (1981)-which was developed independently. There still remain, however, several important findings outside its explanatory domain, so how best to characterize the role of context in conditionedreinforcement value remains an open question (see Williams, 1988, for a review). Nevertheless, delayreduction theory provides a valuable first approximation to a general theory of conditioned value.

\section{Examples of Unresolved Issues}

As noted in the introduction, interest in conditioned reinforcement has waned over the past several years, many apparently considering it a moribund topic of research. That such an opinion is ill-founded is made clear by the following examples of empirical findings which reveal that many different fundamental issues remain to be resolved about both the nature and the determinants of conditioned-reinforcement effects.

Reinforcement rates versus reinforcement delays. The discussion to this point has implicitly assumed that the major determinant of conditioned value is the rate of reinforcement associated with the stimulus, albeit with the complicating factor that the value of a given reinforcement rate varies with the average interreinforcement interval in the situation, as does the strength of Pavlovian conditioning. However, a variety of data suggest that the controlling variable is not rate of reinforcement per se, but, rather, the immediacy to reinforcement signaled by the onset of the stimulus. The empirical basis for this distinction can be exemplified by the results of Killeen (1968), who examined choice in a concurrent chains procedure between, in one terminal link, an FI schedule, and in the alternative terminal link, several mixed-interval schedules, with different sets of interval values. The pattern of obtained preferences was poorly predicted by the arithmetic average of the mixedinterval schedules, which corresponds to the average rate of reinforcement in the presence of that terminallink stimulus. Preference was accurately predicted by the harmonic mean of the different intervals composing the mixed-interval schedule (the mean of the reciprocals of the different times to food), which corresponds to the average immediacy of reinforcement. 
The power of Killeen's (1968) harmonic-mean analysis was extended by Shull, Spear, and Bryson (1981), who demonstrated that the sum of the immediacies of reinforcement controlled choice behavior even when placed in opposition to differences in rate of reinforcement. In their experiment, pigeons received food on a constant VI schedule during a green key color, and could switch to a different schedule associated with red by pecking a changeover key. Once the change occurred, they remained in the presence of the red color for a predetermined period of time (e.g., $3 \mathrm{~min}$ ). The independent variable was the number and location of the reinforcers during red. Choice was found to be well predicted by the sum of the reciprocals of the delays to each individual reinforcer during red, with no evidence of any independent effect of the rate of reinforcement itself. For example, a single reinforcer occurring $30 \mathrm{sec}$ after the choice response was more strongly preferred than two reinforcers occurring at 60 and $90 \mathrm{sec}$, respectively. Similar results have been obtained by Mazur (1986) with his titrating-delay procedure (described earlier) and by Shull, Mellon, and Sharp (1990) with a concurrentchains procedure.

In all of the experiments just described, the delays to reinforcement were calculated with respect to the time after the choice response, which produced the onset of the delay-correlated stimulus. As a result, it was impossible to determine whether the controlling variable was the response-reinforcer delay or the delay from the onset of the stimulus. It is now clear that it is the latter, because variations in the correlation of the stimulus with food (e.g., by providing separate extinction periods for the stimulus), while leaving constant the response-reinforcer delays, strongly affect preference (Dunn, Williams, \& Royalty, 1987). There remains, however, the question as to why the value of a stimulus should be predicted only by the time to reinforcement associated with its onset, instead of by the rates of reinforcement occurring throughout the entire stimulus duration.

This issue is especially troublesome in Mazur's (1991) investigation, described above, of the tradeoff between delay and probability of reinforcement. His finding that a 1.0 probability of reinforcement in combination with a $17-18$-sec delay was equal in value to a .20 probability of reinforcement in combination with a 5 -sec delay (when the same stimulus was associated with both reinforced and nonreinforced presentation of the .20 alternative) implies that the probabilistic alternative was more highly valued than it should be if probability and delay of reinforcement were totally equivalent (which predicts a value of $25 \mathrm{sec}$ in combination with the 1.0 probability). He demonstrated that this effect was predicted by the harmonic-mean form of averaging, under the assumption that nonreinforced stimulus presentations were interpreted simply as parts of long delays, whose length was determined by the total stimulus time since the last reinforcer correlated with that stimulus. Suppose, for example, that the number of non- reinforced trials preceding three separate reinforced trials are 1,4 , and 7 . The corresponding delays to reinforcement would be 10,25 , and 40 (note that the number of trials between successive food presentations is the number of nonreinforced trials + the one reinforced trial, and that all trials are $5 \mathrm{sec}$ in duration); the harmonic mean of these delays to reinforcement is $18 \mathrm{sec}$, in contrast to the arithmetic mean of $25 \mathrm{sec}$. The finding is remarkable because each run of nonreinforced trials could be interrupted by the ITI, the choice phase, and exposure to the alternative stimulus associated with the titrated-delay alternative. The puzzle remains as to how, despite such interruptions, the pigeon could keep track of the accumulated time since the last reinforcement for the probabilistic alternative. Nevertheless, the harmonicmean calculations do accurately describe the obtained pattern of preference.

Stimulus segmentation. Another important determinant of conditioned value is whether the same stimulus is continuously present throughout the temporal distance between the onset of the stimulus and the reinforcer, or whether the delay interval is divided into two separate stimulus segments. An impressive example of this effect has been provided by Leung and Winton (1988), who presented pigeons with a concurrent-chains procedure in which both of the choice alternatives during the initial link were reinforced by access to their individual terminal-link stimuli according to a VI-60-sec schedule. The terminal-link schedules produced by the two choice alternatives were always equal in duration, either FI $15 \mathrm{sec}$ or FI $30 \mathrm{sec}$ across different conditions. The difference between the two terminal links was that one contained the same stimulus throughout the FI, while the other was segmented, such that it was subdivided into two separate stimuli. The point at which the division occurred was then varied across conditions, occurring either early in the FI, in the middle, or near the end. The general finding was that preference was in favor of the unsegmented terminal link, and this effect was stronger with the FI-30-sec schedules than with the FI-15-sec schedules. The degree of preference for the unsegmented alternative also varied strongly with the point of segmentation, and was much stronger when it occurred early in the interval (e.g., during segments of 2 and $28 \mathrm{sec}$ of the total 30 -sec interval).

At a qualitative level, it is not surprising that preference should be greater for the unsegmented alternative. If the unsegmented terminal link is correlated with Stimulus A, and the segmented link with Stimulus B followed by Stimulus C, Stimulus A is directly paired with the primary reinforcer (first-order conditioning), while Stimulus B is paired only with a stimulus that itself has been subject to first-order conditioning, and hence is an example of second-order conditioning. Presumably, therefore, Stimulus B possesses less conditioned value than does Stimulus A, because of the additional associative link. Consequently, choice behavior would be in favor of Stimulus A. Although this general effect of 
stimulus segmentation can be explained by conventional analyses of higher-order conditioning (note, however, that the opposite effect of segmentation occurs in other preparations; cf. Gormezano \& Kehoe, 1982), no extant theory of conditioning provides a basis for understanding why the segmentation effect varies with the temporal location of segmentation in such a powerful fashion. In other words, we have little basic understanding of the quantitative properties of how conditioned value is transmitted across successive stimuli.

The role of motivation. To what extent do the reinforcing effects of conditioned reinforcers persist after the motivational conditions under which they were established have been changed? Early research on this issue yielded conflicting results (see Wike, 1966, for a review), but there is now substantial evidence that behaviors established with conditioned reinforcers are less sensitive to motivational changes than behaviors established with primary reinforcers. Morgan (1974) reviewed the early literature on "resistance to satiation" and noted that there were numerous reports of operant behavior persisting in the face of satiation, despite the animal failing to consume the primary reinforcer once it was attained; he interpreted this as indicating that the operant behavior itself was under the control of conditioned, rather than primary, reinforcement. Rescorla (1977) reported similar findings from an investigation in which rats learned a complex maze and then continued to be run on the maze after being satiated for food. Rescorla noted that the satiated rats became increasingly erratic in their choices, and that an increase in errors occurred near the end of the maze prior to the goalbox before there was any effect on the pattern of behavior early in the maze. Such a pattern is consistent with the interpretation that conditioned-reinforcement effects are less disrupted by motivational changes than those under control of primary reinforcement, under the assumption that responding early in the maze was reinforced by the conditioned-reinforcement properties of access to succeeding segments of the maze.

To the extent that the conditioned-reinforcement properties of a stimulus are due to its Pavlovian association with primary reward, the effects of motivation on conditioned reinforcement should be similar to those obtained within the domain of Pavlovian second-order conditioning. In extensive research devoted to this topic, first-order conditioning involving pairings of S1 with primary reward is followed by $\mathrm{S} 2-\mathrm{S} 1$ pairings that result in conditioning to $\mathrm{S} 2$. Then either the primary reinforcer is devalued (by pairing with an aversive agent or by satiation) or $\mathrm{Sl}$ is extinguished in separate training. The issue has been how behavior to $\mathrm{S} 2$ is then affected without further S2-S1 pairings. When the primary reward itself has been devalued, responding to $S 1$ is typically reduced, while that to $\mathrm{S} 2$ is unaffected (Holland \& Rescorla, 1975). Somewhat more complex results have occurred as a result of $\mathrm{S} 1$ extinction. In the great majority of studies, extinction of S1 has had no direct impact on $\mathrm{S} 2$ responding, the major exception being in the autoshaping procedure in which $\mathrm{S} 1$ and $\mathrm{S} 2$ were different keylights (see Rescorla, 1980, for a review). A critical ingredient appears to be the similarity of S1 and S2, as Sl extinction in the autoshaping preparation also has little effect on $\mathrm{S} 2$ responding when $\mathrm{S} 1$ and $\mathrm{S} 2$ are dissimilar (Nairne \& Rescorla, 1981; see also Holland, 1982, for related data). The implications of these findings for instrumental behavior established/maintained by conditioned reinforcement is uncertain because it is hard to see how the variable of stimulus similarity applies to response-reinforcer contingencies in which the associative elements vary along several different dimensions.

Despite these complexities, the matter of how behavior established under conditioned reinforcement is affected by changes in the value of the reinforcers used to establish such behavior is an issue of great importance. If responses trained with conditioned reinforcers do persist even after abolition of the motivational conditions under which they were originally trained, the implication is that conditioned reinforcers may assume the status of autonomous sub-goals in controlling behavior.

As an example of the practical importance of this possibility, consider the recent analysis of the involvement of conditioned-reinforcement contingencies in the maintenance of smoking behavior, and the consequent implications for smoking-cessation treatments. It is now generally acknowledged that the pharmacological reward properties of nicotine are crucial for maintaining smoking behavior, with the result that nicotine replacement, either by nicotine chewing gum or the nicotine skin patch, has become a major therapeutic approach. While a significant improvement, relative to placebo controls, usually does occur with this approach, the effect is typically small, primarily, it seems, because nicotine replacement has little impact on the degree of craving for cigarettes even though it greatly reduces the number of physiological symptoms associated with smoking withdrawal (e.g., nervousness, weight gain). Rose and Levin (1991) have argued that the basis for the persistence of craving in spite of the continued presence of nicotine is that the sensory properties of smoking have acquired hedonic value in their own right, and it is they, not nicotine itself, which are the object of craving. To support this hypothesis, they review several studies in which various methods mimicking the sensations of smoking (e.g., inhaling aerosols of dilute citric acid) have substantially reduced the level of craving, sometimes to a degree comparable to smoking a commercial cigarette. Their interpretation of this effect is that the sensory properties of smoking have become conditioned reinforcers that retain their hedonic value even when the subject is in the state of nicotine satiation at the physiological level. The implication is that smoking-cessation treatments must consider the conditionedreinforcement properties of smoking-related cues as being as important as, if not more so than, the primary reward properties of nicotine itself. 


\section{Implications for General-Process Learning Theory}

It should be evident that the primary motivation behind this paper has been to resurrect the concept of conditioned reinforcement both as a topic of research and as an explanatory construct. This endeavor comes, in part, from the belief that neglect of the concept has caused important behavioral phenomena to be misinterpreted, often in ways that have been detrimental to the status of behavior theory as a general explanatory framework. To illustrate this, the following two examples will be considered.

Autoshaping. Since its discovery by Brown and Jenkins (1968), autoshaping has served as an important catalyst in the decline of general-process learning theory. The experimental finding that the skeletal response of pecking occurs simply because of the Pavlovian contingency between a localized keylight and food has been taken as convincing evidence both against the validity of Skinner's (1938) distinction between emitted and elicited behavior and, more generally, against the view that Pavlovian and instrumental conditioning reflect distinct types of learning (e.g., Hearst, 1975). The discovery of autoshaping also helped sponsor the theoretical zeitgeist of the 1970s and 1980s, in which all learning effects were explained in the context of the biological predispositions brought by the animal into the laboratory. The impact of autoshaping would have been substantially less, however, if the pecking behavior maintained by autoshaping procedures had been interpreted as being under the control of operant response contingencies.

The finding that pecking behavior in the autoshaping procedure continues under the omission procedure, which cancels food presentations on trials in which pecks are recorded (Williams \& Williams, 1969), has been taken as definitive evidence that operant contingencies cannot explain the effects. However, that finding is persuasive only with respect to contingencies of primary reinforcement. When the role of conditioned reinforcement is considered, a plausible argument can be made that pecking is in fact occurring because of the implicit conditioned-reinforcement contingencies embedded in the procedure.

The critical feature of the autoshaping procedure is that the keylight is paired with food, which is the operation by which the keylight should acquire conditioned value. It is well known that animals, including humans, commonly approach and contact stimuli paired with the reinforcer. The tendency to approach a signal for reward served as the basis for an insightful early theory of maze learning (Deutsch, 1960), and has inspired considerable research under the rubric "sign-tracking" (see Hearst \& Jenkins, 1974, for a review). Conditioned reinforcement provides a plausible account of why such approach occurs. If the animal moves away from the stimulus, its sensory contact with the stimulus is diminished. If it moves toward the stimulus, the degree of the sensory contact increases. Maximum contact with the stimulus and maximum exposure to the conditioned value of the stimulus occur when actual physical contact takes place.
Embedded in the autoshaping procedure are conditionedreinforcement contingencies that encourage increasingly close approach to, and eventually contact with, the stimulus. The fact that pecking behavior continues despite such contacts causing the primary reinforcer of food not to be delivered may then be interpreted as showing only that the power of this conditionedreinforcement contingency is stronger than the delayed primary-reinforcement contingency.

It may be argued that an analysis of autoshaping effects in terms of implicit conditioned-reinforcement contingencies is not critically different from the dominant interpretation in terms of Pavlovian conditioning of the keypeck response. For both accounts, the process of Pavlovian conditioning is crucial for autoshaping to occur. However, the nature by which Pavlovian conditioning has its effect is fundamentally different. Whereas the standard interpretation argues that the motor response itself is elicited by the keylight CS, in much the same way as Pavlov's conditioned response of salivation occurs, the present account assumes that the motor response of approaching and contacting the keylight is shaped by the hedonic value of the keylight, in much the same way as a rat is shaped to leverpress by a food reward. Accordingly, the critical relationship is between the action of approaching the keylight and the resulting increase in sensory feedback from the keylight. Evidence for this interpretation is provided by Wessells (1974), who imposed an omission contingency for approaching the keylight instead of simply pecking it: the CS was terminated (and food was canceled) on trials in which the pigeon came within some criterion distance of the key. Here, unlike the standard omission procedure, approach behavior to the keylight was entirely eliminated (but see Peden, Browne, \& Hearst, 1977, for conflicting results).

Further evidence that conditioned value of the keylight is critical to autoshaping comes from studies of second-order conditioning in which an S1 that did not itself elicit pecking behavior (e.g., a noise) was used to produce pecking to a keylight S2 via S2-S1 pairings in the absence of food. The crucial issue concerns the property of S1 that was transferred to S2, causing keypecking to $\mathrm{S} 2$ to occur. The response learned to $\mathrm{S} 1$ was not transferred, because $\mathrm{S} 1$ behavior did not include pecking. Given Nairne and Rescorla's (1981) finding, described above, that separate extinction of the noise S1 had no effect on $\mathbf{S} 2$ responding, behavior to $\mathrm{S} 2$ was also not due to $\mathrm{S} 1$ serving as an associative mediator causing S2 and food to be directly associated. The remaining interpretation is that $\mathrm{S} 1$ acquired value via its pairing with food, that this value was then transferred to $\mathrm{S} 2$, and that it was this value of S2 that caused S2 keypecking to occur. If autoshaped pecking in second-order procedure is due to the conditioned value of the keylight stimulus, presumably such conditioned value plays an important role in first-order conditioning as well.

An example of the implicit conditioned-reinforcement contingencies in the autoshaping procedure is provided 
by the results of Neuringer and Neuringer (1974; also see Bullock \& Neuringer, 1977) on "social learning" in pigeons. Young pigeons were hand-fed by the experimenters, who subsequently placed the birds in an apparatus with a standard operant response key. Then, while the birds were closely watching the hand of the experimenter, he or she pressed the response key with his or her index finger. Subsequently, the birds were allowed access to the response key, with the measure being how quickly they acquired the pecking response, relative to several different control conditions. The observation by the young birds of the experimenter's finger touching the key significantly facilitated the acquisition of the keypeck response. A plausible interpretation is that the hand of the experimenter had acquired conditioned value via the history of hand feeding, and that this conditioned value was then transferred to the location of the key because of its spatial and temporal contiguity with the finger. Readers familiar with the history of behavior theory will recognize that these dynamics are closely related to Mowrer's (1950, Chapter 24) account of how birds learn to talk, in that the birds shape their vocal output by increasingly close approximations to the sounds associated with sources of positive reinforcement in the environment.

The transfer of value from US to CS is, of course, a well established principle of Pavlovian conditioning. Whether it is sufficient to explain all aspects of autoshaped behavior is open to question-some results do seem to lie outside its range, such as the dependence of the nature of the conditioned response on the nature of the reinforcer (Jenkins \& Moore, 1973); however, the purpose of the present discussion is to demonstrate that a proper appreciation of the potential role of the conditioned-value contingencies may elucidate important behavioral phenomena that have otherwise been regarded as serious challenges to generalprocess learning theory.

Imprinting. The challenge to general-process learning theory that reached a crescendo during the early 1970 s had already been foreshadowed by the discovery of imprinting, which for years had been regarded by ethologists as solid evidence that the rules of learning were specialized with respect to the adaptive demands of the particular animals involved. The crucial features of imprinting were that it occurred only during a welldefined critical period and that the stimulus object present during this critical period formed a template on the animal's nervous system that guided both its later filial behavior and its subsequent choice of mates. Such templates were regarded as having their own rules of formation quite independent of either operant or Pavlovian conditioning.

A very different perspective on imprinting has been offered by Hoffman and Ratner (1973) in a paper that has been seriously neglected until only recently (see Bolhuis, De Vos, \& Kruijt, 1990, for a review of the pertinent evidence). They noted that certain stimuli were innately reinforcing for young animals, as evidenced by distress behavior being terminated by their onset, and by their ability to elicit approach behavior and to serve as a reinforcer for pecking behavior. For young birds, one such stimulus is flickering light, or, more generally, the quick change in illumination patterns across the retina. Movement of stimulus objects in their visual field produces such movement patterns, as does flickering light itself. The conditioned-reinforcement facet of Hoffman and Ratner's account is that, as shown by various tests, the specific features of the imprinted object (e.g., a wooden duck of a particular shape and color) did not themselves have reinforcing properties until paired with the changing light patterns, caused by the object moving. With continued pairings, however, those specific features did acquire the same properties as the flickering light itself. The reason that these conditioning effects were supposedly restricted to a critical period was not that they were confined to a special time period, but rather was because, through maturation, the young birds developed a fear response to novel objects, and the resulting avoidance of such objects prevented the pairings occurring between the particular stimulus features and the movement-induced flickering light. When the birds were not allowed to escape from the imprinted object, "imprinting" was shown to occur well beyond the supposed critical period.

The importance of the conditioned-reinforcement account of imprinting offered by Hoffman and Ratner (1973) is not simply that it provides an explanation of imprinting in terms of the combined effects of Pavlovian and operant conditioning, but also that the process involved is regarded as being generalizable to the socialization of primates as well, the critical difference being the nature of the innately reinforcing stimulus patterns upon which the subsequent learned values are based. Thus, Hoffman and Ratner's account is strongly in the tradition of the accounts of human socialization in terms of learning theory provided by the Hullian school noted in the introduction. Yet their account has received little attention, from either ethologists or learning theorists themselves.

\section{Cognitivism versus Associationism}

In the foregoing discussion, it has been argued that the elaboration of the concept of conditioned reinforcement has major ramifications for many different issues in psychology, ranging from the process of attachment to the functional autonomy of learned motives. Given both the relevance of the concept and its general theoretical utility, it is important to return once more to the reason for its decline in prominence. From this perspective, an important component of this decline has been that the underlying theoretical framework of associationism has fallen into disfavor. Rather than viewing learning as the establishment of associative linkages between individual elements, an increasing number of theorists have propounded the alternative conceptualization that organisms store a veridical record of the actual events that occur in their experience (e.g., Gallistel, 1990; Holyoak, Koh, \& Nisbett, 1989). Behavior is then performed not 
because of "associative strength" but because of a set of performance rules that are superimposed on the underlying "knowledge."

These "representational" accounts of learning are a natural extension of the view, often expressed by cognitive psychologists, that the concepts of conditioning theory are inapplicable to human behavior. An often-cited example is Brewer (1974), who concluded from a review of the conditioning literature with human subjects that conditioned responding did not occur unless the subject was aware of the relation between the CS and US (or the response and reinforcer in operant conditioning). In other words, the subject acquired knowledge about the relation between environmental events, and then performance was determined for motivational reasons that were entirely separate; the concept of associative value was irrelevant.

Recent research argues strongly against this cognitive perspective. In a series of experiments, Baeyens and his collaborators (see Baeyens, Eelen, Crombez, \& van den Bergh, 1992; Baeyens, Eelen, \& van den Bergh, 1990 , for representative experiments and reviews of the literature) have provided strong evidence that the value of an initially neutral stimulus can be either increased or decreased as a function of the value of the following stimulus with which it is paired, without any awareness on the part of the human subject. In a typical experiment of theirs, pictorial slides (which have been of several different types) are divided into the categories of positive value, negative value, and neutral, and then different sets of the neutral slides are followed in their presentation by either the positive or the negative stimuli. The result is that the value of the initially neutral slides is changed in the direction of the stimuli which follow them, as assessed by ratings by the subject after the different types of pairings. These changes have been independent of whether the subject had been aware of the different types of sequences. These results are of major practical importance, because the same basic techniques have been shown to significantly affect the attitudes of consumers in advertising contexts (Stuart, Shimp, \& Engle, 1987).

The findings of Baeyens and his colleagues leave little doubt that both the concept of conditioned value and the concept of conditioned reinforcement derived from it are far more general in their applicability than their critics have appreciated. Moreover, these empirical findings cannot be reduced to the type of cognitivist interpretation that has undermined the appreciation of the theoretical utility of the construct of conditioned reinforcement over the past two decades. The neglect of the concept of conditioned value has been unfortunate, both because of its potential impact on the status of behavior theory as a force in contemporary psychology and because the available evidence speaks strongly in its favor.

\section{REFERENCES}

Baeyens, F, Eelen, P., Crombez, G., \& van den Bergh, O. (1992). Human evaluative conditioning: Acquisition trials, presentation schedule, evaluative style and contingency awareness. Behavior $R e$ search \& Therapy, 30, 133-142.

Baeyens, F., Eelen, P., \& van den Bergh, O. (1990), Contingency awareness in evaluative conditioning: $A$ case for unaware affective evaluative learning. Cognition \& Emotion, 4, 3-18.

Baum, W. M. (1973). The correlation-based law of effect. Journal of the Experimental Analysis of Behavior, 20, 137-153

Bolmuis, J. J., DE Vos, G. J., \& KRUIJT, J. P. (1990). Filial imprinting and associative learning. Quarterly Journal of Experimental Psychology, 42B, 313-329.

Bolles, R. C. (1967). Theory of motivation. New York: Harper \& Row

BRANCH, M. N. (1977). Signalled and unsignalled percentage reinforcement of performance under a chained schedule. Journal of the Experimental Analysis of Behavior, 25, 71-83.

BREWER, W. F. (1974). There is no convincing evidence for operant or classical conditioning in adult humans. In W. B. Weimer \& D. S Palermo (Eds.), Cognition and symbolic processes. Hillsdale, NJ: Erlbaum.

Brown, P. L., \& JENKIns, H. M. (1968). Auto-shaping of the pigeon's keypeck. Journal of the Experimental Analysis of Behavior, 11, 1-8.

Bullock, D., \& Neuringer, A. (1977). Social learning by following: An analysis. Journal of the Experimental Analysis of Behavior, 25, 127-135.

Catania, A. C., \& Keller, K. J. (1981). Contingency, contiguity, correlation, and the concept of causation. In P. Harzem \& M. D. Zeiler (Eds.), Advances in the analysis of behaviour: Vol. 2. Predictability, correlation, and contiguity (pp. 125-167). Chichester, U.K.: Wiley.

Chance, P. (1994). Learning \& behavior (3rd ed.). Pacific Grove, CA: Brooks/Cole

Cronin, P. B. (1980). Reinstatement of postresponse stimuli prior to reward in delayed-reward discrimination learning by pigeons. Animal Learning \& Behavior, 8, 352-358.

DALY, H. B. (1969). Learning of a hurdle-jump response to escape cues paired with reduced reward or frustrative nonreward. Journal of Experimental Psychology, 79, 146-157.

Deutsch, J. A. (1960). The structural basis of behavior. Cambridge: Cambridge University Press.

Dollard, J., \& Miller, N. E. (1950). Personality and psychotherapy: An analysis in terms of learning, thinking and culture. New York: McGraw-Hill.

Domjan, M., \& BuRKHARD, B. (1986). The principles of learning and behavior (2nd ed.). Pacific Grove, CA: Brooks/Cole.

Dunn, R., Williams, B., \& Royalty, P. (1987). Devaluation of stimuli contingent on choice: Evidence for conditioned reinforcement. Journal of the Experimental Analysis of Behavior, 48, 117-131.

Durlach, P. J. (1989). Learning and performance in Pavlovian conditioning: Are failures of contiguity failures of learning or performance? In S. B. Klein \& R. R. Mowrer (Eds.), Contemporary learning theories: Pavlovian conditioning and the status of traditional learning theory (pp. 19-59). Hillsdale, NJ: Erlbaum.

FANTINO, E. (1969). Choice and rate of reinforcement. Journal of the Experimental Analysis of Behavior, 12, 723-730

FANTINo, E. (1977). Conditioned reinforcement: Choice and information. In W. K. Honig \& J. E. R. Staddon (Eds.), Handbook of operant behavior (pp. 313-339). Englewood Cliffs, NJ: Prentice-Hall.

Gallistel, C. R. (1990). The organization of learning. Cambridge, MA: MIT Press

GibBon, J., \& Balsam, P. (1981). Spreading association in time. In C. M. Locurto, H. S. Terrace, \& J. Gibbon (Eds.), Autoshaping and conditioning theory (pp. 219-253). New York: Academic Press.

GolluB, L. R. (1970). Information on conditioned reinforcement: A review of Conditioned reinforcement edited by $\mathrm{D}$. Hendry. Journal of the Experimental Analysis of Behavior, 14, 361-372.

Gormezano, I., \& KEHOE, E. J. (1982). Associative transfer in classical conditioning to serial compounds. In M. L. Commons, R. J. Herrnstein, \& A. R. Wagner (Eds.), Quantitative analyses of behavior: Acquisition (Vol. 3, pp. 297-322). Cambridge, MA: Ballinger Press.

HeARST, E. (1975). Pavlovian conditioning and directed movements. In G. Bower (Ed.), The psychology of learning and motivation (Vol. 9, pp. 215-262). New York: Academic Press. 
Hearst, E., \& Jenkins, H. M. (1974). Sign tracking: The stimulusreinforcer relation and directed action. Austin, TX: The Psychonomic Society.

Herrnstein, R. J. (1977). The evolution of behaviorism. American Psychologist, 32, 593-603.

Herrnstein, R. J., \& Loveland, D. H. (1972). Food-avoidance in hungry pigeons and other perplexities. Journal of the Experimental Analysis of Behavior, 18, 369-383.

HofFMAN, H. S., \& RATNER, A. M. (1973). A reinforcement model of imprinting: Implications for socialization in monkeys and man. Psychological Review, 80, 527-546.

HOLLAND, P. C. (1982). Interelement associations in serial compound conditioning. In M. Commons, R. J. Herrnstein, \& A. Wagner (Eds.), Quantitative analyses of behavior: Acquisition (Vol. 3, pp. 323-345). Cambridge, MA: Ballinger Press.

HOLLAND, P. C., \& Rescorla, R. A. (1975). The effect of two ways of devaluing the unconditioned stimulus after first- and second-order appetitive conditioning. Journal of Experimental Psychology: Animal Behavior Processes, 1, 355-363.

HOLYOAK, K. J., KoH, K., \& NISBETT, R. E. (1989). A theory of conditioning: Inductive learning within rule-based default hierarchies. Psychological Review, 96, 315-340.

Jenkins, H. M., \& MoOrE, B. R. (1973). The form of the autoshaped response with food or water reinforcers. Journal of the Experimental Analysis of Behavior, 20, 163-181.

Kelleher, R. T. (1966). Conditioned reinforcement in second-order schedules. Journal of the Experimental Analysis of Behavior, 9 475-485.

Keller, F. S., \& Schoenfeld, W. N. (1950). Principles of psychology. New York: Appleton-Century-Crofts.

KilleEN, P. (1968). On the measure of reinforcement frequency in the study of preference. Journal of the Experimental Analysis of Behavior, 11, 263-269.

KIMBLE, G. A. (1961). Hilgard and Marquis' conditioning and learning. Englewood Cliffs, NJ: Prentice-Hall.

Kish, G. B. (1966). Studies of sensory reinforcement. In W. K. Honig (Ed.), Operant behavior: Areas of research and application (pp. 109-159). New York: Appleton-Century-Crofts.

LATTAL, K. A., \& GleEson, S. (1990). Response acquisition with delayed reinforcement. Journal of Experimental Psychology: Animal Behavior Processes, 16, 27-39.

LEUNG, J.-P., \& Winton, A. S. W. (1988). Preference for simple interval schedules of reinforcement in concurrent chains: Effects of segmentation ratio. Journal of the Experimental Analysis of Behavior, 49, 9-20.

Lieberman, D. A., Davidson, F. H., \& Thomas, G. V. (1985). Marking in pigeons: The role of memory in delayed reinforcement. Journal of Experimental Psychology: Animal Behavior Processes, 11, 611-624.

Lieberman, D. A., McIntosh, D. C., \& Thomas, G. V. (1979). Learning when reward is delayed: A marking hypothesis. Journal of Experimental Psychology: Animal Behavior Processes, 5, 224-242.

Mackintosh, N. J. (1974). The psychology of animal learning. New York: Academic Press.

MaCKIntosh, N. J. (1983). Conditioning and associative learning. New York: Oxford University Press.

MAZUR, J. E. (1986). Choice between single and multiple delayed reinforcers. Journal of the Experimental Analysis of Behavior, 46, 67-77.

MazUR, J. E. (1991). Choice with probabilistic reinforcement: Effect of delay and conditioned reinforcers. Journal of the Experimental Analysis of Behavior, 55, 63-77.

MazUR, J. E. (1993). Predicting the strength of a conditioned reinforcer: Effects of delay and uncertainty. Current Directions in Psychological Science, 2, 70-74.

Miller, N. (1951). Learnable drives and rewards. In S. S. Stevens (Ed.), Handbook of experimental psychology (pp. 435-472). New York: Wiley.

Miller, N. E., \& Dollard, J. (1941). Social learning and imitation. New Haven: Yale University Press.

Morgan, M. J. (1974). Resistance to satiation. Animal Behavior, 22, 449-466.
MOWRER, O. H. (1950). Learning theory and personality dynamics. New York: The Ronald Press.

NaIRNe, J. S., \& Rescorla, R. A. (1981). Second-order conditioning with diffuse auditory reinforcers in the pigeon. Learning \& Motivation, 12, 65-91.

NeURINGER, A., \& Neuringer, M. (1974). Learning by following a food source. Science, 184, 1005-1008.

Pearce, J. M., \& Collins, L. (1987). An evaluation of the associative strength of a partially reinforced serial CS. Quarterly Journal of Experimental Psychology, 39B, 273-293.

Peden, B. F., Browne, M. P., \& Hearst, E. (1977). Persistent approaches to a signal for food despite food omission for approaching. Journal of Experimental Psychology: Animal Behavior Processes, 3, 377-399.

Preston, R. A., \& Fantino, E. (1991). Conditioned reinforcement value and choice. Journal of the Experimental Analysis of Behavior, $55,155-175$.

Rachlin, H. (1976). Behavior and learning. San Francisco: W. H. Freeman.

Rachlin, H., Logue, A. W., Gibbon, J., \& Frankel, M. (1986). Cognition and behavior in studies of choice. Psychological Review, 93, 33-45.

Rescorla, R. A. (1977). Pavlovian second-order conditioning: Some implications for instrumental behavior. In H. Davis \& H. M. B. Hurwitz (Eds.), Operant-Pavlovian interactions (pp. 133-164). Hillsdale, NJ: Erlbaum.

Rescorla, R. A. (1980). Pavlovian second-order conditioning: Studies in associative learning. Hillsdale, $\mathrm{NJ}$ : Erlbaum.

RESCORLA, R. A. (1982). Effect of a stimulus intervening between CS and US in autoshaping. Journal of Experimental Psychology: Animal Behavior Processes, 8, 131-141.

Rose, J. E., \& Levin, E. (1991). Inter-relationships between conditioned and primary reinforcement in the maintenance of cigarette smoking. British Journal of Addiction, 86, 605-609.

Royalty, P., Williams, B. A., \& Fantino, E. (1987). Effects of delayed conditioned reinforcement in chain schedules. Journal of the Experimental Analysis of Behavior, 47, 41-56.

SCHAAL, D. W., \& BRANCH, M. N. (1988). Responding of pigeons under variable-interval schedules of unsignaled, briefly signaled, and completely signaled delays to reinforcement. Journal of the Experimental Analysis of Behavior, 50, 33-54.

SCHAal, D. W., \& Branch, M. N. (1990). Responding of pigeons under variable-interval schedules of signaled-delayed reinforcement: Effects of delay-signal duration. Journal of the Experimental Analysis of Behavior, 53, 103-121.

SCHUSTER, R. H. (1969). A functional analysis of conditioned reinforcement. In D. Hendry (Ed.), Conditioned reinforcement (pp. 192234). Homewood, IL: Dorsey Press.

Shull, R. L., Mellon, R. C., \& Sharp, J. A. (1990). Delay and number of food reinforcers: Effect on choice and latencies. Journal of the Experimental Analysis of Behavior, 53, 235-246.

Shull, R. L., SPEAR, D. J., \& Bryson, A. E. (1981). Delay or rate of food delivery as a determiner of response rate. Journal of the Experimental Analysis of Behavior, 35, 129-143.

SizemORE, O. J., \& LATTAL, K. A. (1978). Unsignalled delay of reinforcement in variable-interval schedules. Journal of the Experimental Analysis of Behavior, 30, 169-175.

SKINNER, B. F. (1938). The behavior of organisms. New York: AppletonCentury-Crofts.

SKINNER, B. F. (1953). Science and human behavior. New York: Free Press.

StadDon, J. E. R. (1983). Adaptive learning and behavior. Cambridge: Cambridge University Press.

Stuart, E. W., Shimp, T. A., \& Engle, R. W. (1987). Classical conditioning of consumer attitudes: Four experiments in an advertising context. Journal of Consumer Research, 14, 334-349.

Wessells, M. G. (1974). The effects of reinforcement upon the prepecking behaviors of pigeons in the auto-shaping experiment. Journal of the Experimental Analysis of Behavior, 21, 125-144.

WIKE, E. L. (1966). Secondary reinforcement: Selected experiments. New York: Harper \& Row.

WILliams, B. A. (1971). The effects of intertrial interval on discrimi- 
nation reversal learning in the pigeon. Psychonomic Science, 23, 241-243.

Williams, B. A. (1976a). The effects of unsignalled delayed reinforcement. Journal of the Experimental Analysis of Behavior, $\mathbf{2 6}$ 441-449.

WILLIAMS, B. A. (1976b). Short-term retention of response outcome as a determinant of serial reversal learning. Learning \& Motivation, 7, 418-430.

WILliaMS, B. A. (1981). Invariance in reinforcements to acquisition, with implications for the theory of inhibition. Behaviour Analysis Letters, 1, 73-80.

Williams, B. A. (1988). Reinforcement, choice, and response strength. In R. C. Atkinson, R. J. Herrnstein, G. Lindzey, \& R. D. Luce (Eds.), Stevens' handbook of experimental psychology (2nd ed., pp. 167-244). New York: Wiley.

Williams, B. A. (1991a). Behavioral contrast and reinforcement value. Animal Learning \& Behavior, 19, 337-344.

WILLIAMS, B. A. (1991b). Marking and bridging versus conditioned reinforcement. Animal Learning \& Behavior, 19, 264-269.
Williams, B. A., \& Dunn, R. (1991a). Preference for conditioned reinforcement. Journal of the Experimental Analysis of Behavior, $\mathbf{5 5}$, 37-46.

Williams, B. A., \& DunN, R. (1991b). Substitutability between conditioned and primary reinforcers in discrimination acquisition. Journal of the Experimental Analysis of Behavior, 55, 21-35.

Williams, D. R., \& Williams, H. (1969). Automaintenance in the pigeon: Sustained pecking despite contingent non-reinforcement. Journal of the Experimental Analysis of Behavior, 12, 511-520.

ZIMMERMAN, J., HANFORD, P. V., \& BROWN, W. (1967). Effects of conditioned reinforcement frequency in an intermittent free-feeding situation. Journal of the Experimental Analysis of Behavior, 10, 331340 .

(Manuscript received January 5, 1994; revision accepted for publication July 8,1994 .) 